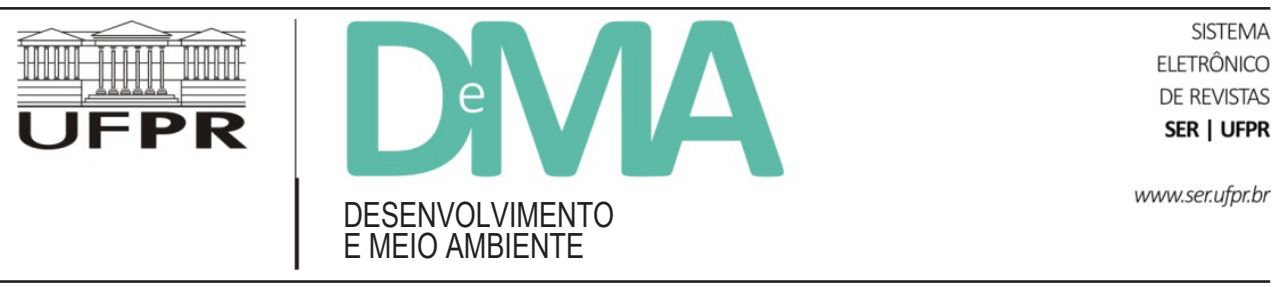

\title{
Para onde nos guia a mão invisível? Considerações sobre os paradoxos do modelo econômico hegemônico e sobre os limites ecológicos do desenvolvimento
}

\section{Where is the Invisible Hand Guiding Us? Considerations about the Paradoxes of the Hegemonic Model and the Ecological Limits of Development}

\author{
Carolina Lopes ARAUJO ${ }^{1 *}$, Elimar NASCIMENTO ${ }^{1}$, João Nildo de Souza VIANNA ${ }^{1}$ \\ ${ }^{1}$ Centro de Desenvolvimento Sustentável (CDS), Universidade de Brasília (UnB), Brasília, DF, Brasil. \\ *E-mail de contato: carolinalopesaraujo@yahoo.com.br
}

Artigo recebido em 2 de dezembro de 2013, versão final aceita em 15 de julho de 2014.

RESUMO

A dinâmica do crescimento econômico contínuo vigente no capitalismo financeiro tem se mostrado incompatível com os limites planetários. A humanidade se encontra em um impasse ético, econômico e tecnológico. O modelo de produção e consumo vigente se mostra insuficiente para assegurar condições de vida digna para toda a humanidade no presente e aponta para uma deterioração dessas condições em um futuro próximo. Este artigo realiza uma revisão bibliográfica de trabalhos clássicos na teoria do desenvolvimento sustentável e, por meio da abordagem crítica da economia capitalista, coloca em xeque o conceito hegemônico do progresso e aponta a insuficiência do paradigma do crescimento para assegurar o desenvolvimento sustentável. Mesclando e conjugando as ideias dos principais autores dessas áreas, o artigo conclui que a sustentabilidade do desenvolvimento requer condicionantes que, ao longo do tempo, se tornam mais difíceis de serem alcançados. A dinâmica atual do sistema econômico leva a desgastes ambientais com efeitos cada vez mais severos, que serão sentidos especialmente a partir de 2030, podendo chegar a um colapso antes de 2100 , comprometendo a capacidade de sobrevivência humana no planeta. A sustentabilidade, a suficiência e a equidade do desenvolvimento exigem uma mudança estrutural no paradigma de produção e de consumo. Para tanto, se fazem necessários mecanismos sociais, institucionais e informacionais, além da adequação e da coordenação dos avanços tecnológicos.

Palavras-chave: desenvolvimento sustentável; Antropoceno; progresso; limites do planeta; crescimento econômico.

ABSTRACT The current economic dynamics of continuous growth in financial capitalism has proved incompatible with the planetary boundaries. Humanity faces an ethical, economic and technological impasse. The current model of production and consumption are insufficient to ensure decent living conditions for all mankind in the present and tends towards deterioration of these conditions in the near future. This paper provides a literature review of classic studies on the theory of sustainable development and, through the critical approach of the capitalist 
economic theory, questions the hegemonic concept of progress, and reveals the insufficiency of the paradigm of growth to ensure sustainable development. Putting together the lessons from main authors of these areas, this paper concludes that sustainable development requires conditions that have become more difficult to achieve. The current dynamics of the economic system leads to environmental depletion with increasingly severe effects that will be felt especially after 2030 , which could conduce to collapse before 2100 , undermining the human survival on Earth. Sustainable, sufficient and equitable development requires structural change in production and consumption paradigm. In this sense, social, institutional and informational mechanisms are imperatives and it requires proper and coordinated technological advances.

Keywords: sustainable development; Antropocene; progress; planetary boundaries; economic growth.

\section{Introdução}

A obra Silent Spring, de Rachel Carson (2010)', publicada pela primeira vez em 1962, inaugurou uma sequência de publicações que discutem as ameaças sobre as propriedades ecológicas do planeta oriundas dos modos de consumo e produção vigentes. As preocupações expostas na obra de Carson foram reforçadas pela publicação de Limites do crescimento (Meadows et al., 1978), encomendada ao Massachusetts Institute of Technology pelo Clube de Roma e publicada originalmente em inglês no ano 1972, tendo sido traduzida para 28 idiomas desde então, dada sua importância. $\mathrm{O}$ cerne da questão quanto à sustentabilidade está nos valores que sustentam a noção de prosperidade e bem-estar da sociedade contemporânea. Evidenciando a necessidade de colocar em xeque esses valores, Jackson (2011) se questiona, no título de sua publicação, se seria possível pensar a "prosperidade sem crescimento".

Já é consenso científico (Constanza et al., 2012), político (Pnuma, 2011) e na sociedade civil (Comissão Carta da Terra, 2000) que o crescimento econômico infinito não é possível em um planeta finito. Tampouco há dúvidas sobre os efeitos das atividades humanas sobre as características naturais da Terra. Há séculos a humanidade vem transformando profundamente o planeta. Por causa dessas transformações, alguns autores propõem que estamos vivendo uma era geológica chamada de Antropoceno (Pnuma, 2011; Buarque, 2012a; Constanza et al., 2012; Sachs, 2012). Segundo Clémençon (2012), a Era do Antropoceno se caracteriza por transformações profundas e irreversíveis causadas pelo ser humano sobre as características naturais do planeta derivadas da aceleração dos ciclos produtivos e de consumo, desde a Revolução Industrial, e agravada pela explosão demográfica mundial iniciada nos anos 50 do século XX.

A ideia de progresso associado a riquezas financeiras, que no sistema capitalista não encontra limites para sua (auto)reprodução, materializa-se na acumulação de bens materiais. No entanto, essa noção de progresso vai de encontro aos limites do planeta quanto ao fornecimento de recursos que subsidiam a produção e o consumo. Diante de um paradoxo causado pela pressão para a geração de riquezas contínua e constante (por meio da produção e do consumo) e pela necessidade de se respeitar a capacidade de suporte do planeta em oferecer recursos naturais aplicados às atividades humanas, a humanidade é convidada a construir um novo modelo de desenvolvimento, que se apresente sustentável tanto no horizonte sincrônico (para as diversas populações que convivem temporalmente no planeta) como diacrônico (respeitando-se os direitos de desenvolvimento das futuras gerações).

Mas quais seriam as características do modelo de desenvolvimento que permita atender às necessidades humanas de forma equitativa e includente, ao tempo em que se apresente ambientalmente viável?

\section{O paradigma da prosperidade e os desafios para a vida humana no planeta}

Os efeitos nocivos das ações humanas sobre o meio ambiente podem ser sentidos pelas populações,

${ }^{1}$ Publicada no Brasil sob o título Primavera silenciosa, pela editora Gaia (última edição publicada em 2010). 
especialmente aquelas que vivem em condições econômicas mais desfavoráveis (Francophonie \& IEPF, 2012). Segundo dados do Banco Mundial sobre a realidade do desenvolvimento em 2010, 20,6\% da população vive com menos de US\$ 1,25 por dia, $21 \%$ da população urbana mundial não tem acesso aos serviços de saneamento básico (World Bank, 2012) e 11\% não tem acesso à água potável (Valentim, 2010).

Mas esses efeitos não se restringem aos limites geográficos ou das classes sociais e atualmente mostram sua mais agravada face na forma de mudanças climáticas e das perdas de biodiversidade (Pnuma, 2011). Os estudos quanto à "pegada ecológica" alertam para a insustentabilidade dos modos de consumo da maioria dos países desenvolvidos e chamam a atenção para o fato de que, se ainda é possível a sobrevivência humana no planeta, isso se deve às imensas desigualdades sociais que privam de condições de vida decente uma grande parcela da população (Global Footprint Network, 2010; GPS/ONU, 2012).

No entanto, o desenvolvimento da Ásia e de outros países emergentes insere uma enorme parcela da humanidade no consumo de massa. Nesse contexto, Léna (2012) alerta para o fato de que estamos diante de uma mudança de escala dos problemas do desenvolvimento, o que se traduz em níveis de pressão inimagináveis sobre os recursos naturais e os ecossistemas.

Ao tempo que não se pode negar à população dos países emergentes o acesso ao nível de consumo até então gozado por uma minoria privilegiada, tampouco é possível negar a responsabilidade histórica da presente civilização quanto aos rumos do desenvolvimento e seus legados para as gerações futuras. Diante de um impasse ético, econômico e tecnológico, a humanidade é chamada a assumir a sua responsabilidade: o "seu modo de vida rompeu o equilíbrio essencial entre o homem e o ecossistema, colocando em perigo a resiliência do planeta e a sobrevivência de milhões de pessoas e espécies vivas" (Francophonie \& IEPF, 2012, p. 26).

No entanto, na busca do enfrentamento dos problemas gerados pelo modelo de desenvolvimento embasado no crescimento econômico, as propostas incitam à aceleração do próprio crescimento (Aktouf, 2004). Jackson (2011) explica que o imperativo de crescimento fornece as bases para o modelo econômico moderno. Desse modo, o crescimento é apontado como o mecanismo padrão para evitar o colapso do sistema, que por sua vez é tomado como aquele responsável por oferecer bem-estar e satisfação à sociedade.

"A expansão da cultura industrial instilou em praticamente todas as comunidades do planeta o desejo e a expectativa de um crescimento material permanente" (Meadows et al., 2007, p. 203). No senso comum, um pujante desenvolvimento econômico representa melhores escolhas e incremento do que chamamos de qualidade de vida da sociedade. No entanto, os fatos revelam que os benefícios da aceleração e do crescimento econômicos têm sido sistematicamente mal distribuídos e carregam em si custos ambientais e sociais expressivos. Jackson (2011, p. 11) denuncia que a "estreita busca pelo crescimento representa uma terrível distorção do bem comum e dos valores que fundamentam a humanidade".

Mas, sequer os males resultantes do modelo econômico hegemônico têm sido suficientes para refutar as promessas de que o crescimento econômico é o caminho para o progresso e a prosperidade (Francophonie \& IEPF, 2012). Jackson (2011) reitera que esse modelo de desenvolvimento é instável ecologicamente e, também, economicamente. A opção da sociedade por este modelo consiste em uma acintosa irresponsabilidade que encerra a humanidade naquilo que o autor denomina de "gaiola de ferro do consumismo". Ele explica que o modelo econômico hegemônico somente é viável enquanto se preserva a liquidez do sistema e se mantêm níveis elevados de consumo. Para tanto, é preciso dinamizar o crescimento econômico por meio da inovação e da destruição criativa - o que é consonante com a prática da obsolescência programada - e da expansão da demanda por novidades disponíveis no mercado na forma de produtos e/ou serviços. Esses dois fatores propulsores da dinâmica de mercado se retroalimentam e carecem continuamente de disponibilidade de capital. A fonte primária desse capital reside no progresso constante do poder aquisitivo (Léna, 2012). Por meio da poupança, os consumidores financiam o crédito e, por meio do consumo, eles financiam os lucros das empresas. Acontece que tal dinâmica é demasiadamente instável, porque está fundamentada em ganhos crescentes e infinitos.

Primeiramente, essa instabilidade deriva-se da busca incessante por eficiência produtiva, o que significa, 
em termos econômicos, redução de custos de produção. Para tanto, investe-se em tecnologias que economizam recursos e trabalho. A economia de recursos materiais é condizente com a proposta do desacoplamento (decoupling), da qual trataremos mais adiante. Já a redução em gastos com mão de obra reduz o poder aquisitivo da população e, por consequência, o capital disponível no mercado consumidor, drenando a demanda que impulsiona o sistema (Jackson, 2011, p. 62).

Além disso, diante do sinal de um enfraquecimento, seja por escassez de capital ou pelo aumento dos preços das matérias-primas, o sistema inverte seus ciclos de retroalimentação, se dirigindo para o colapso: diante de sinais de recessão, o crédito fica menos atraente e as pessoas tendem a poupar, ao invés de consumir. Isso também leva à desaceleração do sistema. Para combater as ameaças de colapso econômico, os governos tendem a enfrentar a crise com três soluções: flexibilização monetária (e consequente inflação), dívida pública e dívida privada. Consequências nefastas dessas tentativas de ajustes são o aumento do desemprego, o aumento da dívida externa dos países e o aumento da dívida privada, que são gerados e, ao mesmo tempo, levam à criação de uma bolha especulativa insustentável no longo prazo. Como resultado, tem-se "Estados e cidadãos enfraquecidos diante da indústria financeira internacionalizada" (Léna, 2012, p. 26), o que leva ao seguinte questionamento: no que, afinal, consiste essa "prosperidade" que está sendo gerada pelo sistema?

Mesmo diante das evidências da fragilidade do sistema, "os discursos pelo desenvolvimento giram em torno da necessidade de crescimento" (Léna, 2012, p. 30). "Questionar o crescimento é tomado como um ato de lunáticos, idealistas e revolucionários” (Jackson, 2011, p. 102). De fato, a sociedade se vê presa em um profundo dilema: resistir ao crescimento e enfrentar o colapso econômico ou avançar no progresso econômico, colocando em risco o bem-estar da sociedade (desigualdades) e a sobrevivência da raça humana (e outras espécies) sobre o planeta (poluição)?

Buarque (2012b) propõe que a impossibilidade de sair desse paradoxo deve trazer a percepção de que a origem do problema está no próprio conceito de progresso. De fato, para além da perspectiva econômica, progresso ou prosperidade, conforme colocado por Jackson (2011, p. 102), consiste na capacidade de se realizar enquanto ser humano, dentro dos limites ecológicos de um planeta finito.

\section{Os limites do planeta e os cenários do desenvolvimento}

Antes de adentrarmos na discussão sobre os limites do crescimento, é preciso chamar a atenção para uma assertiva de Bursztyn (1994): "é bom não esquecer uma questão essencial: as necessidades humanas são consumidoras de natureza". Por essa razão, Veiga (2011) alerta que, mesmo havendo um avanço tecnológico que permita a otimização da eficiência produtiva e a desmaterialização da produção, não é possível aliviar a pressão absoluta sobre os recursos naturais ao tempo em que se mantém o crescimento econômico. Assim, o dilema do crescimento não se desfaz diante das promessas da desmaterialização da economia ou do descolamento (decoupling) do crescimento econômico do uso de recursos naturais, ainda que assim esteja postulado na proposta do PNUMA quanto à economia verde (Pnuma, 2011).

Mesmo que o descolamento deva ser encorajado e estimulado para que se possa mitigar as pressões sobre os recursos naturais, Constanza et al. (2012) reconhecem que a proposta do decoupling tem limitações significativas. Conforme alerta Veiga (2011), na dinâmica econômica não se pode pensar a tecnologia isolada dos dois outros fatores: a população e o nível de consumo. Dessa forma, se mantida a tendência de crescimento necessária para alimentar a dinâmica econômica como visto anteriormente, não é possível reduzir o impacto ambiental meramente por meio de avanços tecnológicos e ganhos de eficiência produtiva.

Tomando a segunda lei da termodinâmica, tem-se que a entropia é o limite que condiciona as transformações materiais e energéticas no planeta (Georgescu-Roegen, 1999). Desse modo, a eficiência produtiva trata fundamentalmente de eficiência energética. A capacidade de suporte do planeta é limitada pelo fluxo energético necessário para compensar o desgaste causado pelas atividades humanas sobre fontes de recursos renováveis e sumidouros de poluição. Observa-se um gradativo aumento da quantidade de energia e capital necessários 
para sustentar os fluxos de materiais requeridos pela economia, o que dá sinais de esgotamento desses recursos e serviços ambientais. Quando a exploração das fontes e sumidouros se tornar energética e financeiramente inviável, a economia começará a se retrair e as condições de vida se deteriorarão, podendo levar a dois resultados: uma redução nas condições de vida da sociedade que permita a regeneração das condições naturais do planeta ou, caso essas condições tenham sido degradadas de modo irreversível, o colapso do sistema, com severos prejuízos para a sociedade, podendo comprometer a capacidade de sobrevivência humana sobre a Terra (Ward \& Dubos, 1973; Meadows et al., 2007).

Para a manutenção das condições de vida no planeta, é preciso assegurar a capacidade de resiliência do planeta, isto é: recursos renováveis, que deverão ter taxa de regeneração maior ou igual à taxa de uso; recursos não renováveis, que deverão ser substituídos por recursos renováveis a taxas maiores ou iguais à sua utilização; e a absorção de poluentes, que deverão apresentar taxas de neutralização ou reciclagem superiores às taxas de emissão (Meadows et al., 2007). No entanto, os índices de consumo, de expansão populacional e emissão de poluentes apresentam um crescimento exponencial abrupto, especialmente a partir da metade do século XX, negligenciando a capacidade de regeneração e suporte do planeta (Global Footprint Network, 2010).

Wackernagel (1994), em sua tese de doutorado, afirma que existe um limite, por ele denominado de ecological bottom-line, dentro do qual a dinâmica econômica pode existir sem comprometer a capacidade de regeneração da natureza. Tal limite é imperativo, uma vez que as perdas na capacidade de suporte natural do planeta não podem ser compensadas por adventos criados pelo homem. No entanto, o autor alerta que nem sempre é fácil identificar quando os limites foram ultrapassados, uma vez que eles são frouxos, permitindo que excessos sejam mantidos por um determinado período. Tal situação além dos limites naturais é denominada estado de overshoot.

Meadows et al. (1992) denunciaram, em 1992, que os limites do planeta já foram ultrapassados. Diante de um estado de overshoot experimentado especialmente desde a metade do século XX, faz-se necessária uma profunda alteração nos padrões de vida, produção e consumo da sociedade para que ela volte a atuar dentro dos limites planetários naturais. Rockström et al. (2009) apontam nove fronteiras dentro das quais a humanidade precisa operar para assegurar sua capacidade de sobrevivência. Ainda que o tamanho dessas fronteiras seja impreciso e de difícil quantificação, os estudos de Rockström et al. (2009) e da Rede Global da Pegada Ecológica (Global Footprint Network, 2010) demonstram que a humanidade já ultrapassou pelo menos três dessas fronteiras, quais sejam: a interferência nos ciclos de nitrogênio, devido à aplicação de fertilizantes em culturas agrícolas; o comprometimento da biodiversidade, com perdas irreversíveis de espécies essenciais para a manutenção do equilíbrio ecológico; e as emissões de $\mathrm{CO}_{2}$ na atmosfera, com impactos sobre as mudanças climáticas. Além disso, o limite de acidificação dos oceanos está próximo de ser ultrapassado e as fronteiras para o uso da água doce e para o uso da terra mostram sinais de vulnerabilidade.

As causas do estado de overshoot ecológico são diversas e complexas. O Relatório Meadows (Meadows et al., 1978) resume essas causas em três comportamentos insustentáveis: o rápido crescimento exponencial da economia e da população, a negligência dos limites além dos quais a vida no planeta fica comprometida e o atraso no desenvolvimento e na implementação de respostas tecnológicas às limitações naturais do planeta.

Na proposta de compreender a dinâmica de crescimento em um mundo finito, o relatório identificou cinco variáveis do desenvolvimento que interagem entre si em ciclos de retroalimentação positiva e negativa (Meadows et al., 1978), quais sejam: população, industrialização, produção de alimentos, uso de recursos não renováveis e poluição. Por meio de um software intitulado World3 (World3 Simulator, 2008), buscou-se observar a dinâmica de interação e de alteração não linear dessas variáveis ao longo do tempo, considerando as tendências de comportamento apresentadas desde 1900. As cinco variáveis são analisadas por meio de onze índices estatísticos. A manipulação desses índices permite a criação de cenários do desenvolvimento. As características desses cenários foram sintetizadas na configuração de onze características do sistema resultantes. As variáveis, os índices que alimentam o simulador World3 e as resultantes características dos cenários estão sintetizados na Tabela 1 a seguir. 
TABELA 1 - Variáveis e resultantes do modelo World3-03, de Meadows et al. (2007).

\begin{tabular}{lll}
\hline Variáveis Analisadas & Índices Alimentação World3 & Características dos cenários \\
\hline \multirow{2}{*}{ População Mundial } & Crescimento Populacional & População \\
\cline { 2 - 3 } & Fertilidade & Produção de alimentos \\
\hline \multirow{2}{*}{ Industrialização } & Produção Industrial & Produção industrial \\
\cline { 2 - 3 } & Capital aplicado em serviços & Poluição persistente \\
\cline { 2 - 3 } & Trabalho & Uso de recursos não renováveis \\
\hline \multirow{2}{*}{ Produção de alimentos } & Alimentos & Alimentos per capita \\
\cline { 2 - 3 } & Investimento em agricultura & Bens de consumo per capita \\
\cline { 2 - 3 } & Terras usadas na agricultura & Serviços per capita \\
\hline Esgotamento dos recursos & Fertilidade da terra para agricultura & Expectativa de vida \\
\cline { 2 - 3 } & Recursos não renováveis & Indicador de bem-estar humano \\
\hline Poluição & Poluição & Pegada ecológica \\
\hline
\end{tabular}

FONTE: Elaboração dos autores.

Passados 30 anos desde a simulação original, o grupo encabeçado por Donella Meadows revisitou as variáveis analisadas e ajustou os valores para retratarem suas variações reais ao longo do período e melhor indicarem suas tendências de comportamento (Meadows et al., 2007).

Da composição de cenários construídos por Meadows et al. (1978; 2007), tem-se que os efeitos nocivos da manutenção de um estado de overshoot serão sentidos com severidade por toda a população mundial (ainda que seus efeitos possam variar segundo a cultura, a classe social, situação econômica e/ou posição geográfica) a partir de 2030, se mantido o modelo de desenvolvimento usual.

Um cenário de sustentabilidade, que colocasse o planeta novamente dentro de seus limites naturais, somente seria possível se uma série de condicionantes do desenvolvimento fosse experimentada simultaneamente a partir dos primeiros anos do século XXI. Se alguma dessas condicionantes não estiver presente, segundo o modelo World3 não será possível evitar o colapso do sistema, o qual deve ocorrer mesmo antes de 2100. Tais condicionantes, que deveriam estar presentes a partir de 2002, são: que o estoque de recursos não renováveis acessível fosse o dobro do que se estima presentemente; que se implantassem tecnologias e parâmetros para o efetivo e severo controle da poluição mantida nos níveis verificados na metade dos anos 70; que se aplicassem tecnologias para a melhoria da produtividade agrícola conciliadas a tecnologias e políticas de proteção do solo contra a erosão; que houvesse avanços significativos na economia de recursos naturais aplicados à produção $(d e-$ coupling); que o tamanho das famílias fosse limitado a dois filhos por família, para assegurar uma população estável em 7,5 bilhões de pessoas; que a produção industrial per capita fosse estabilizada em níveis $10 \%$ superiores àqueles verificados no ano 2000 e que a pegada ecológica mundial fosse diminuída para respeitar a capacidade de suporte do meio ambiente global (Meadows et al., 2007).

O cenário de sustentabilidade, no qual se verifica a presença das condicionantes acima mencionadas, é um cenário de equilíbrio, o que não significa estagnação. Tampouco se propõe que economia e população sejam estáticas, mas que haja um balanço entre ciclos positivos e negativos e que os estoques principais do planeta (fontes e sumidouros) sejam mantidos estáveis. Manter as atividades humanas dentro dos limites do sistema 
confere compensações e opções, o que não é possível diante de uma situação de colapso eminente. Para tanto, são necessários mecanismos sociais, institucionais e informacionais potentes e a adequação e coordenação dos avanços tecnológicos. Contudo, cada ano de atraso no início de uma transição na direção do equilíbrio reduz a atratividade das compensações e opções que se apresentam disponíveis no futuro, isto é, "demora significa colapso" (Meadows et al., 2007, p. 254). É urgente que a sociedade tome consciência das consequências de suas escolhas e consiga implementar os avanços tecnológicos em prol da sustentabilidade. Mas, essa tomada de consciência exige uma ruptura com a lógica do contexto de exigências permanentes por crescimento econômico.

\section{A revolução para a sustentabilidade e os mecanismos necessários ao desenvolvimento sustentável}

Meadows et al. (2007) destacam a impossibilidade do planeta de suportar uma pegada ecológica em índice superior a 1,0 por muito tempo, isto é, que a taxa de utilização humana dos recursos naturais mantenha-se dentro da capacidade de suporte do planeta. Atualmente, o planeta experimenta uma taxa de pegada ecológica de 1,51, segundo o Relatório Planeta Vivo (WWF et al., 2012). Tão logo os limites da sustentabilidade tenham sido atingidos, as diminuições são inevitáveis por causa do comprometimento das condições de vida sobre a Terra. Para se evitar o colapso e corrigir o estado de overshoot, são necessárias políticas de desenvolvimento globais comprometidas com o futuro. Sobretudo, é importante começar o quanto antes!

Não há dúvidas de que o modelo de produção e consumo vigente é insustentável e de que o paradigma da prosperidade é excludente e produz efeitos perigosos e irreversíveis para o equilíbrio ecológico e social mundialmente (Boulding, 1966; Latouche, 1986; CMMAD, 1991; ONU, 1992; Constanza et al., 2012; United Nations, 2012). "O sucesso da Revolução Industrial criou finalmente sua própria escassez, gerando a necessidade de uma nova revolução": a revolução da sustentabilidade (Meadows et al., 2007, p. 266). Meadows et al. (2007, p. 269) afirmam que "sustentabilidade, suficiência e equidade exigem mudança estrutural no sistema". Essas novas características não somente são viáveis, como elas podem representar um mundo desejável.

Jackson (2011, p. 98) propõe ser necessário confrontar a estrutura do sistema e redefinir o conceito de prosperidade para que ele melhor traduza uma situação de vida na qual o ser humano possa desenvolver suas potencialidades. Em seus estudos, o autor busca uma correlação entre os níveis de crescimento econômico e de renda per capita e dimensões materiais e não materiais do bem-estar social (expectativa de vida, nível de educação, mortalidade infantil) e conclui que claramente não há evidências de que o crescimento econômico aumenta a prosperidade. De fato, ele constata estatisticamente que, a partir de certo nível de crescimento, os ganhos tendem a se estabilizar ou até mesmo decrescer.

Dessa maneira, o crescimento econômico contínuo tem se mostrado insuficiente para gerar níveis crescentes de bem-estar para a sociedade, além de colocar ameaças sobre o equilíbrio ecológico do planeta. Faz-se necessário, portanto, revisar os valores que orientam os comportamentos sociais e a economia, para que passem a responder melhor aos anseios sociais por um mundo equitativo, seguro, justo e sustentável. Torna-se imprescindível incorporar nesses valores a noção de responsabilidade compartilhada entre governos, cidadãos e entidades de mercado por um estilo de vida e de produção e consumo que se atenha aos limites planetários.

No entanto, Veiga e Issberner (2012, p. 131) constatam que a transformação dos padrões de comportamentos sociais míopes e egoístas em decisões mais altruístas não ocorre espontaneamente apenas com conscientização quanto aos riscos e prejuízos de um modelo insustentável de desenvolvimento. Por causa disso, Jackson (2011) afirma ser necessária a construção coletiva de um sistema de governança para a prosperidade. Isso serviria de ferramenta para transição em direção a um modelo de desenvolvimento marcado pelos conceitos de prosperidade compartilhada, capital social, bens comuns e cooperação. Tal modelo carece de uma nova lógica de funcionamento da macroeconomia que respeite os limites ecológicos e viabilize a todos os seres humanos desenvolverem suas potencialidades. Meadows et al. (2007) defendem que tal sistema de governança deve carregar em si regras funcionais a serviço das liberdades 
e autonomia, com vistas a promover um desenvolvimento qualitativo, equitativamente distribuído e que respeite a diversidade cultural e étnica da sociedade, ao mesmo tempo em que permite colocar a criatividade humana a serviço do progresso social e moral e não mais a serviço do mercado, como tem ocorrido.

\section{Considerações finais}

Segundo Löwy (2012, p. 147), "a crise econômica e a crise ecológica resultam do mesmo fenômeno: um sistema que transforma tudo - a terra, a água, o ar que respiramos, os seres humanos - em mercadoria" e que se fundamenta no padrão de expansão contínua da economia e acumulação crescente de capital. Esse sistema apresenta claros sinais de esgotamento, o que tem levado às crises financeiras experimentadas em vários países desenvolvidos a partir de 2008. Além disso, o sistema demonstra também insuficiência em fornecer prosperidade, uma vez que é gerador de iniquidades e outros problemas sociais e ambientais.

Urge, portanto, encontrar um modelo alternativo de desenvolvimento que melhor atenda aos anseios da sociedade por um mundo melhor para todos e sustentável ao longo do tempo. As bases para o questionamento do sistema vigente estão lançadas e se mostram nos discursos defendidos pelos movimentos sociais de resistência ao modelo econômico hegemônico. No entanto, tais movimentos não revelaram potencial de transformar,

\section{Referências}

Aktouf, O. Pós-globalização, administração e racionalidade econômica: a síndrome do avestruz. São Paulo: Atlas, 2004. ISBN 85-224-3680-0.

Boulding, K. E. The Economics of the Coming Spaceship Earth. In: Jarret, H. (Ed.). Environmental Quality in a Growing Economy. Baltimore: The Johns Hopkins Press for Resources for the Future, 1966.

Buarque, C. Desafios à humanidade: perguntas para a Rio+20. Curitiba: Ibpex, 2012a. 176 p. ISBN 978-85-7838-926-0. em escala planetária, o modo de pensar e agir quanto ao desenvolvimento, de modo a imputar-lhe sustentabilidade. De fato, sequer foi possível um conceito robusto de sustentabilidade que adjetive o desenvolvimento e, então, possa fundamentar uma teoria sobre o desenvolvimento sustentável (Nascimento, 2012). O paradigma econômico está incrustado nos valores e nas concepções da sociedade, o que dificulta o necessário abandono da obsessão pelo crescimento contínuo. Vigora fortemente o medo da crise econômica e de seus efeitos nefastos sobre as condições de vida da sociedade, o que oculta o fato de que é esse próprio sistema o causador das mazelas que afligem a sociedade.

Se ainda não estão disponíveis os conceitos e as ferramentas para a implementação de um novo modelo de desenvolvimento, veem-se lampejos de um futuro desejado pela sociedade. O "futuro que queremos" está sendo discutido em escala global (United Nations, 2012). Compete aos diversos atores sociais assumirem, com urgência, suas responsabilidades compartilhadas e diferenciadas e orquestrarem comportamentos, esforços, recursos e saberes na construção coletiva e inclusiva dos mecanismos sociais, institucionais e informacionais que, contrapondo-se à manutenção do modelo business as usual, possam conduzir a tal futuro profícuo. Tardar em agir nesse sentido é condenar a humanidade a experimentar os efeitos nefastos desse padrão civilizatório (Morin, 2010) que, pouco a pouco, e irreversivelmente, transforma a Terra em um planeta pleno de mercadorias, porém inóspito à vida.

\section{2012b.}

O progresso da ideia do progresso. Brasília, 20 mar

Bursztyn, M. Armadilhas do progresso: contradições entre economia e ecologia. Sociedade e Estado, 10(1), 97-124, jan.-jul. 1994

Carson, R. A. A primavera silenciosa. São Paulo: Gaia, 2010.

Clémençon, R. Welcome to the Anthropocene: Rio+20 and the Meaning of Sustainable Development. Journal of Environment \& Development, 21(3), 27, set. 2012. Disponível em: 
$<$ http://jed.sagepub.com/content/21/3/311.abstract $>$. Acesso em: 16/03/2013.

CMMAD. Nosso Futuro Comum. 2. ed. Rio de Janeiro: FGV, 1991. Disponível em: <http://pt.scribd.com/doc/12906958/ Relatorio-Brundtland-Nosso-Futuro-Comum-Em-Portugues > . Acesso em: 17/02/2013.

Comissão Carta da Terra. Carta da Terra. Eco-92. Terra, C. D. Rio de Janeiro: Comissão Carta da Terra, 2000.

Constanza, R. et al. Building a Sustainable and Desirable Economy-in-Society-in-Nature. New York: United Nations Division for Sustainable Development, 2012. 94 p. Disponível em: <http://www.un.org/esa/dsd/dsd_sd21st/21_pdf/ Building_a_Sustainable_and_Desirable_Economy-in-Societyin-Nature.pdf $>$. Acesso em: 06/07/2012.

Francophonie; IEPF. Note de Décryptage des enjeux de la Conférence Rio +20: mettre au monde une économie verte équitable e une gouvernance démocratique de la planète dans un cadre de dévelopement durable. Paris: Association 4D, 2012. 150 p. Disponível em: <http://www.association4d.org/ IMG/pdf_20120618_NdD_Rio_20_VF_sans_annexe.pdf $>$. Acesso em: 05/06/2012.

Georgescu-Roegen, N. The Entropy law and the Economic Process. Boston: Harvard University Press, 1999.

Global Footprint Network. The Ecological Wealth of Nations: Earth's biocapacity as a new framework for international cooperation. Oakland (CA): Global Footprint Network, 2010

GPS/ONU. Povos resilientes, planeta resiliente: um futuro digno de escolha. New York: Nações Unidas, 2012.

Jackson, T. Prosperity without growth. Earthscan Pubns Ltd., 2011. 286 p.

Latouche, S. Faut-il refuser le développement? Paris: PUF, 1986.

Léna, P. Os limites do crescimento e a busca pela sustentabilidade: uma introdução ao debate. In: ; Nascimento, E. (Ed.). Enfrentando os limites do crescimento: sustentabilidade, decrescimento e prosperidade. Rio de Janeiro: Garamond, 2012. cap. 2, p. 23-43.

Löwy, M. Crise ecológica e crise de civilização: a alternativa ecossocialista. In: Léna, P.; Nascimento, E. (Ed.). Enfrentando os limites do crescimento: sustentabilidade, decrescimento e prosperidade. Rio de Janeiro: Garamond, 2012. cap. 7, p. 147156. ISBN 978-85-7617-256-7.

Meadows, D. H.; Meadows, D. L.; Randers, J. Beyond the Limits: confronting global collapse, envisioning a sustainable future. Vermont: Chelsea Publishing Co., 1992.
. Limites do crescimento: a atualização de 30 anos. Rio de Janeiro: Qualitymark, 2007.

et al. Limites do crescimento. 2. ed. São Paulo: Perspectiva, 1978.

Morin, E. Pourquoi il nous faut une politique de civilisation. Cahier de l'IIRPC, IV, n. Au-delà du développement, 2010.

Nascimento, E. P. Trajetória da sustentabilidade: do ambiental ao social, do social ao econômico. Estudos Avançados [on line], 26(74), p. 51-64, 2012. Disponível em: <http:// www.scielo.br/scielo.php?script=sci_arttext\&pid=S0103$-40142012000100005 \& \operatorname{lng}=\mathrm{en} \& \mathrm{nrm}=\mathrm{iso}>$. Acesso em: $30 / 04 / 2012$.

ONU. Agenda 21 Global. Conferência das Nações Unidas sobre o Meio Ambiente e Desenvolvimento (Rio 92) (CNUMAD). Rio de Janeiro: Ministério do Meio Ambiente (MMA), Brasil, 1992.

Pnuma. Caminhos para o desenvolvimento sustentável e a erradicação da pobreza - síntese para tomadores de decisão: Programa das Nações Unidas para o Meio Ambiente, 2011.

Rockström, J. et al. Planetary boundaries: exploring the safe operating space for humanity. Ecology and Society, 14(2), 32, 2009. Disponível em: <http://www.ecologyandsociety.org/ vol14/iss2/art32/>. Acesso em: 19/01/2013.

Sachs, I. De volta à mão invisível: dos desafios da Segunda Cúpula da Terra no Rio de Janeiro. Estudos Avançados [on line], 26, 5-20, 2012. Disponível em: <http://www.scielo.br/scielo. php?script=sci_pdf\&pid=S0103-40142012000100002\&lng= en\&nrm=iso\&tlng=pt $>$. Acesso em: 30/04/2012.

United Nations. The Future We Want: outcome of the United Nations Conference on Sustainable Development. United Nations Conference on Sustainable Development - Rio+20. Rio de Janeiro (Brasil), 2012. 53 p.

Valentim, H. T. Cotexto e contexto: formas linguísticas e possibilidades de interpretação do enunciado. In: Marçalo, M. J.; Lima-Hernandes, M. C. et al. (Ed.). Língua Portuguesa: ultrapassar fronteiras, juntar culturas. Évora: Universidade de Évora, 2010. p.279-296.

Veiga, J. E. D. O grande embaraço da Rio - 2012. Revista Fevereiro, 3, jun. 2011. Disponível em: $<$ http://www.revistafevereiro.com/index.php>. Acesso em: 09/05/2012.

; Issberner, L.-R. Decrescer crescendo. In: Léna, P.; Nascimento, E. (Ed.). Enfrentando os limites do crescimento: sustentabilidade, decrescimento e prosperidade. Rio de Janeiro: Garamond, 2012. cap. 5, p.107-134. 
Wackernagel, M. Ecological Footprint and Appropriated Carrying Capacity: A Tool for Planning Toward Sustainability. Vancouver (Canada), (PhD Thesis) - School of Community and Regional Planning, The University of British Columbia, 1994.

Ward, B.; Dubos, R. Uma terra somente: a preservação de um pequeno planeta. São Paulo: Melhoramentos, 1973.

World3 Simulator. World 3-03 Simulator: based on the model used in "Limits to Growth: the 30-year update". Apresenta a simulação dos cenários apresentados no livro Limites do Cres- cimento: uma atualização de 30 anos, 2008. Disponível em: $<$ http://www.world3simulator.org/>. Acesso em: 20/012013.

World Bank. World Development Indicators 2012. World Bank-free PDF, 2012.

WWF et al. Living Planet Report 2012: Biodiversity, biocapacity and better choices. Gland (Switzerland): WWF International, 2012. Disponível em: $<$ http://www.footprintnetwork. org/images/uploads/LPR_2012.pdf $>$. Acesso em: 20/03/2013. 